\title{
Resíduos da construção civil em pequenas obras: uma análise sob a ótica do design
}

Mateus Szomorovszky (Currículo Lattes) Anna Luiza Moraes de Sá Cavalcanti (Currículo Lattes) Marli Teresinha Everling (Currículo Lattes)

\section{INTRODUÇÃO}

O homem, com suas atividades, vem alterando cenários naturais, degradando o meio ambiente e gerando uma quantidade exagerada de resíduos na busca por matéria-prima para o seu sustento físico, psíquico e econômico.

A Associação Brasileira de Limpeza Pública e Resíduos Especiais (ABRELPE, 2010) estima no Brasil um montante de aproximadamente cem mil toneladas de resíduos de construção civil produzidos em apenas um dia. Essas perdas de materiais de construção nas obras resultam do desperdício durante o seu processo de execução e dos restos de materiais que são perdidos por danos no recebimento, 
transporte e armazenamento. Desse valor, cerca de $90 \%$ dos resíduos gerados, que são suscetíveis de reaproveitamento e reciclagem, são desperdiçados pelas obras (AGOPYAN; JOHN, 2012). Considerando a contínua geração dos RESÍDUOS DA CONSTRUÇÃO CIVIL (RCC), pensar um novo processo de reaproveitamento torna-se de suma importância ambiental, social e financeira, no sentido de que estes retornem para a obra em substituição a novas matérias-primas que seriam extraídas do meio ambiente. Trata-se de uma atividade que deve ser prioritariamente realizada no próprio canteiro, mas que deve também ser executada fora dele, antes da obra, na otimização dos projetos, e após a obra, por meio do correto descarte.

Este artigo foi realizado a partir da pesquisa para o projeto de conclusão do Mestrado Profissional em Design na Univille. Com base na experiência dos autores no campo da arquitetura, frequentemente nos canteiros das obras que projeta, além de conversas casuais com construtores e empreiteiras, e de observações in loco para a elaboração deste trabalho, foi percebido que o acondicionamento dos resíduos nas pequenas construções e reformas ainda é feito de forma precária, desde a entrada dos insumos, sem o cuidado com o local de armazenagem, até posteriormente com a saída do resíduo; este é retirado por meio de sacos de lixo ou transportado diretamente pelo carrinho de mão até a caçamba coletora. Não há uma preocupação com a separação e limpeza dos ambientes, tampouco com as leis vigentes, como a Resolução no. 307 (de 5 de julho de 2002) do Conselho Nacional do Meio Ambiente (CONAMA), que estabelece diretrizes, critérios e procedimentos para a gestão dos resíduos da construção civil, cujos geradores são responsáveis pela caracterização dos resíduos, triagem, acondicionamento, transporte e destinação. 
Com base no exposto, o artigo apresenta conceitos inerentes ao Design de Serviços e à sustentabilidade, que podem contribuir para solucionar o problema de separação, acondicionamento e o transporte interno de resíduos da construção civil (RCC) de pequeno porte.

\section{SUSTENTABILIDADE E DESIGN}

Segundo o site do Ministério do Meio Ambiente, a Agenda 21 protocolada na Conferência Rio-92, pode ser definida como um instrumento de planejamento para a construção de sociedades sustentáveis, em diferentes bases geográficas, que concilia métodos de proteção ambiental, justiça social e eficiência econômica, ou seja, construir sem afetar o meio ambiente.

Autores como Pinto (2005), Roaf (2006) e Rogers (2013) defendem no design e na arquitetura um ciclo de vida sustentável para minimizar os impactos decorrentes de suas ações, com a configuração de um circuito fechado, com todos os subprodutos sendo reutilizados.

Associando o conceito do ciclo de vida sustentável à área da construção civil, o resultado seria a redução do descarte de materiais e dos impactos ambientais, a diminuição de custos da cadeia de produção, baixa barreira legal e a demanda crescente por uso do reciclado', conforme Figura 1.

1 Disponível em: <http://www.recinertambientale.com.br/>. Acesso em: 24 mar. 2015. 
Figura 1 - Fluxograma do ciclo ideal da construção civil

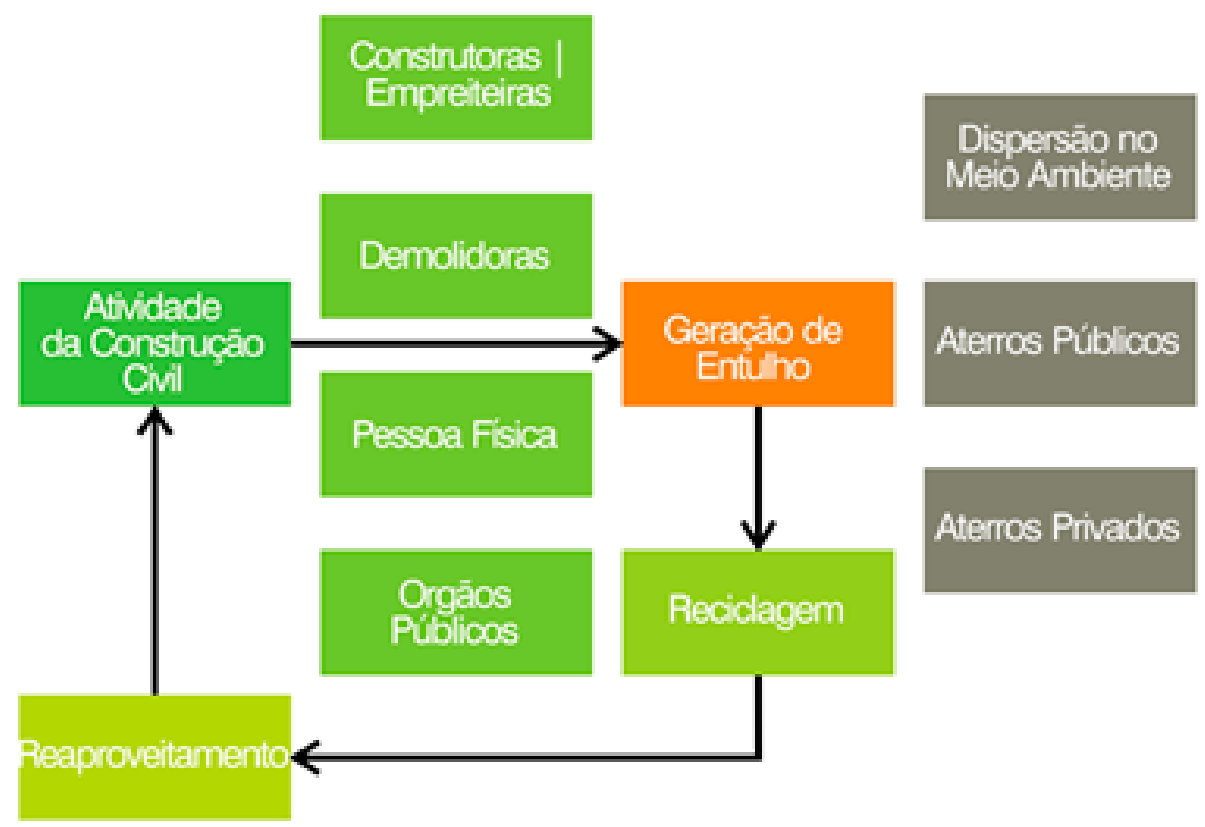

Fonte: adaptado de Recinert Ambientale (2015)

Apesar desse entendimento, Pinto (2005) aponta que as indústrias modernas ainda operam segundo paradigmas que foram desenvolvidos sem uma percepção mais abrangente da natureza, sem levar em conta a saúde, a complexidade e a interconectividade dos sistemas naturais na agenda do design industrial. Ademais, segundo Walker (2005 apud SOUZA, 2007, p. 31):

Apesar da disponibilidade de tecnologias sofisticadas, a abordagem atual do design, produção e distribuição dos produtos continua sendo a mesma, onde (sic) os recursos são extraídos da natureza processados, transformados em partes, montados como produtos, distribuídos em larga escala, usados, descartados e, por fim, substituídos. 
Um ciclo de vida não sustentável apresenta-se como modelo linear, tendo como resultante o desperdício. Para eliminar o conceito de desperdício, torna-se necessário projetar coisas-produtos, embalagens e sistemas-dentro do entendimento inicial de que o desperdício não existe.

O termo Design para a sustentabilidade pode ser definido, no sentido mais amplo, como uma prática de design, educação e pesquisa, que pode contribuir para o desenvolvimento sustentável. Portanto, com base nessa definição, faz-se necessário buscar uma solução para o acondicionamento dos RCC, desde a sua origem, no canteiro de obras, de maneira com que o novo serviço seja benéfico para toda a cadeia (VEZZOLI, 2010).

Nas últimas décadas verifica-se que a história da cultura e da prática do design passou por diversas mudanças, sobretudo no que se refere à sustentabilidade, passando do desenvolvimento "de produtos isolados para sistemas de produção de consumo, e de problemas estritamente ambientais para a mistura complexa de questões sociais e ambientais" (MANZINI apud VEZZOLI, 2010, p. 11). Em meados dos anos 90, o foco do design estava no nível do produto, no baixo impacto ambiental, conhecido como Product Life Cycle Design ou Ecodesign. Na virada do século foi definido como Design para Inovação de Sistemas Ecoeficientes. Recentemente, a pesquisa em design levou a discussão sobre o possível papel do design para equidade e coesão social (VEZZOLI, 2010).

Para as empresas, a mudança afeta a cultura corporativa, que passa a exigir um novo modelo de negócios, e, para os governos, a necessidade de definição e implementação de políticas que facilitem o andamento dos negócios das empresas. Em relação às cidades que já estão engajadas em um movimento de sustentabilidade, Rogers (2013) destaca: 
[...] as sociedades urbanas estão desenvolvendo estratégicas adequadas à sua cultura e necessidades específicas. Em cada uma delas, há um pressuposto fundamental: os cidadãos querem interferir na conformação das suas cidades. De forma enfática, elas provam que a participação popular aliada a um efetivo compromisso do poder público podem transformar a estrutura social e física de nossas cidades (ROGERS, 2013, p. 20).

Essas mudanças sociais já acontecem, e isso se reflete em como o design vê o mercado e como se pode intervir com mais eficiência na busca de um design voltado à sustentabilidade. Essa mudança transforma as metodologias utilizadas e norteia uma evolução de um simples pensar ecológico a um sistema inteiro para sustentabilidade. Em todo o processo é preciso pensar como avaliar o impacto ambiental, como reduzir o uso de recursos, como aperfeiçoar a vida do produto e estender a vida dos materiais, facilitar a desmontagem e a diminuição da geração de resíduos.

As preocupações de Vezzoli (2010) vêm ao encontro do que Pinto (2005) e Lima e Lima (2009) comentam em seus manuais de boas práticas para a construção civil, sobre a redução do impacto ambiental e da importância da análise do ciclo de vida dos materiais, nesse caso, a redução do resíduo e seu correto descarte.

Com isso, é possível associar esses conceitos com o design de Produto/Serviços, baseados em Zeithalm (2014) e Souza (2008). Anteriormente, a gestão de serviços era mais incidente nos setores bancários, de saúde e de hospitalidade, hoje se expandiu para setores de tecnologia, varejistas, bens de consumo e setor produtivo.

No caso dos RCC, faz-se necessário buscar novas ferramentas que aperfeiçoem o gerenciamento do resíduo, principalmente nas pequenas obras. As pessoas, cada vez mais, procuram serviços que solucionem seus problemas de uma maneira mais amigável, otimizada, transparente e sustentável. 
É um exemplo do que acontece atualmente com aplicativos de smartphones que estão quebrando paradigmas e monopólios até então intocados, como as empresas Airbnb², Uber ${ }^{3}$ e Alibaba ${ }^{4}$, líderes nos seus respectivos mercados, as quais não possuem sequer uma unidade do que vendem (quartos de hotel, táxis e estoque, respectivamente). A dificuldade na oferta de serviços com valores agregados colocam as empresas diante de desafios, como adequações socioculturais, inovações tecnológicas, entre outros fatores que 'modificam' a lógica do serviço antes prestado (SOUZA, 2008).

Quando adequamos esse pensamento aos serviços hoje prestados na construção civil, observa-se no canteiro que o cliente quer sua obra finalizada, limpa e entregue no prazo, independentemente do impacto ambiental e social causado, apesar de buscar elementos ecológicos na elaboração de projeto (aquecimento solar, reaproveitamento de água da chuva etc.) que justifiquem um pensamento sustentável. Tanto as empresas quanto os clientes devem adaptar-se às novas demandas sociais e ambientais e fazer com que todos os agentes participem do processo ativamente, sabendo como será a obra, quais os reais custos e o que será feito com o resíduo descartado.

Para o entendimento do design de serviços associado ao tema do presente trabalho, foi elaborado um fluxograma (Figura

\footnotetext{
2 Airbnb é um mercado comunitário confiável para pessoas anunciarem, descobrirem e reservarem acomodações ao redor do mundo, seja por computador, seja por tablet ou celular. Disponível em: <www.airbnb.com.br/about/about-us $>$.

3 Uber: conecta diretamente passageiro e motorista por meio de um aplicativo, gerando demanda por serviços compartilhados e novas possibilidades para a mobilidade urbana. Disponível em: <http://www.uber.com/pt/about>.

${ }^{4}$ Fornece tecnologia e serviços que permitem que os consumidores e comerciantes possam conduzir, por meio de um servidor único, compra e venda de produtos. Disponível em: $<$ http://alibabagroup.com/en/about/overview>.
} 
2) abrangendo o recorte de estudo, desde o descarregamento do insumo na parte externa do edifício, passando pela entrega (no interior do edifício), chegando à acomodação do insumo no local da obra, o manuseio dos artefatos, a geração dos resíduos e o acondicionamento, até a saída do resíduo para a coleta.

Figura 2 - Infográfico do ciclo de entrada e saída de insumo

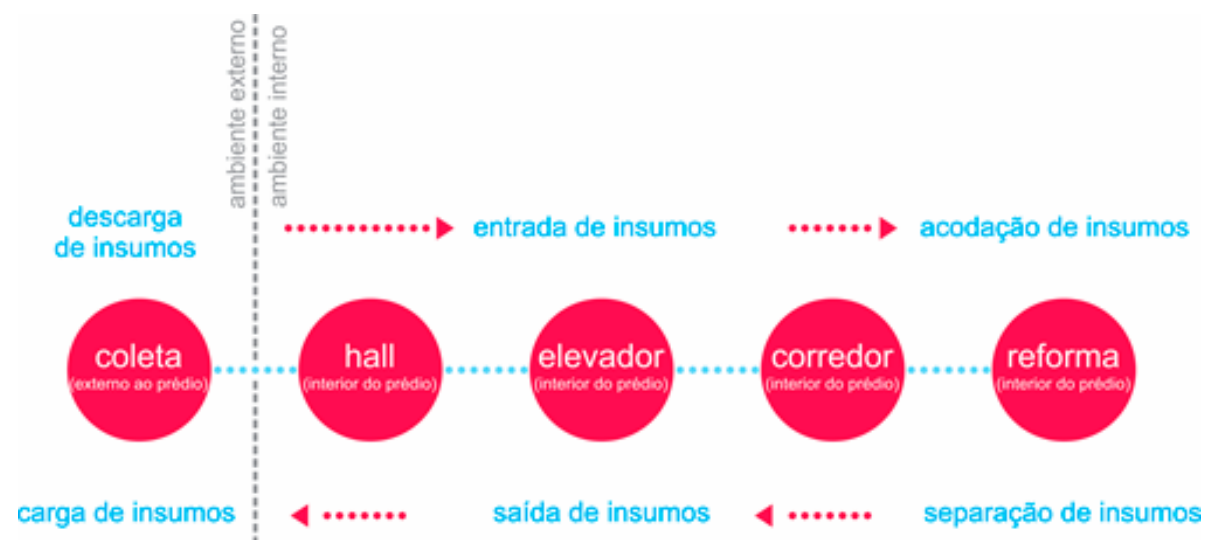

Fonte: elaborada pelos autores (2015)

O serviço de coleta, separação e o transporte interno dos resíduos da construção civil de pequeno porte, objeto de estudo desta investigação, se enquadram nas características do Design de sistemas para ecoeficiência, proposto na metodologia de Vezzoli (2010), que atende a uma demanda particular promovendo uma inovação específica, menos radical e com menos inovação tecnológica, mas focada na criação de novas interações e parcerias, objetivando a sustentabilidade, visto que:

[...] o design pode se tornar um efetivo agente promotor da sustentabilidade, pois o designer é o ator social que, pela natureza da sua profissão, é mediador privilegiado, entre artefatos e pessoas, na relações cotidianas e expectativas de bem-estar a elas atreladas (MANZINI apud VEZZOLI, 2010, p. 11). 
Assim, o papel do designer é articular todas as etapas de desenvolvimento de projeto, evidenciando a ecoeficiência nas etapas desse processo, desenvolvendo sistemas capazes de atender a seus clientes, engajando-os em interações inovadoras na busca da ecoeficiência (VEZZOLI, 2010).

\section{PROPOSTA DE SERVIÇO PARA A COLETA E ACONDICIONAMENTO DE RESÍDUOS DA CONSTRUÇÃO CIVIL EM PEQUENAS OBRAS}

Após analisar a jornada do resíduo, foram utilizadas ferramentas do design thinking no desenvolvimento da proposta de um sistema orientado para a sustentabilidade e a avaliação ambiental, socioética e econômica dos RCC.

Para a análise do sistema, foi utilizada uma planta de uma edificação hipotética de um edifício de apartamentos, pois esse tipo de edificação seria o mais complexo para otimização do serviço, visto que em shopping centers, salas comerciais e residências unifamiliares já existem espaços internos, mesmo que improvisados, para o acondicionamento dos RCC.

A proposta de serviço foi pensada em três etapas: a primeira, utilização de um espaço no corredor de cada andar para um pequeno depósito, a fim de acondicionar os dispositivos para os RCC, além de prateleiras de uso comum, onde haveria ferramentas manuais e elétricas para uso comum (Figura 3). 
Figura 3 - Planta baixa| depósito de utilidades

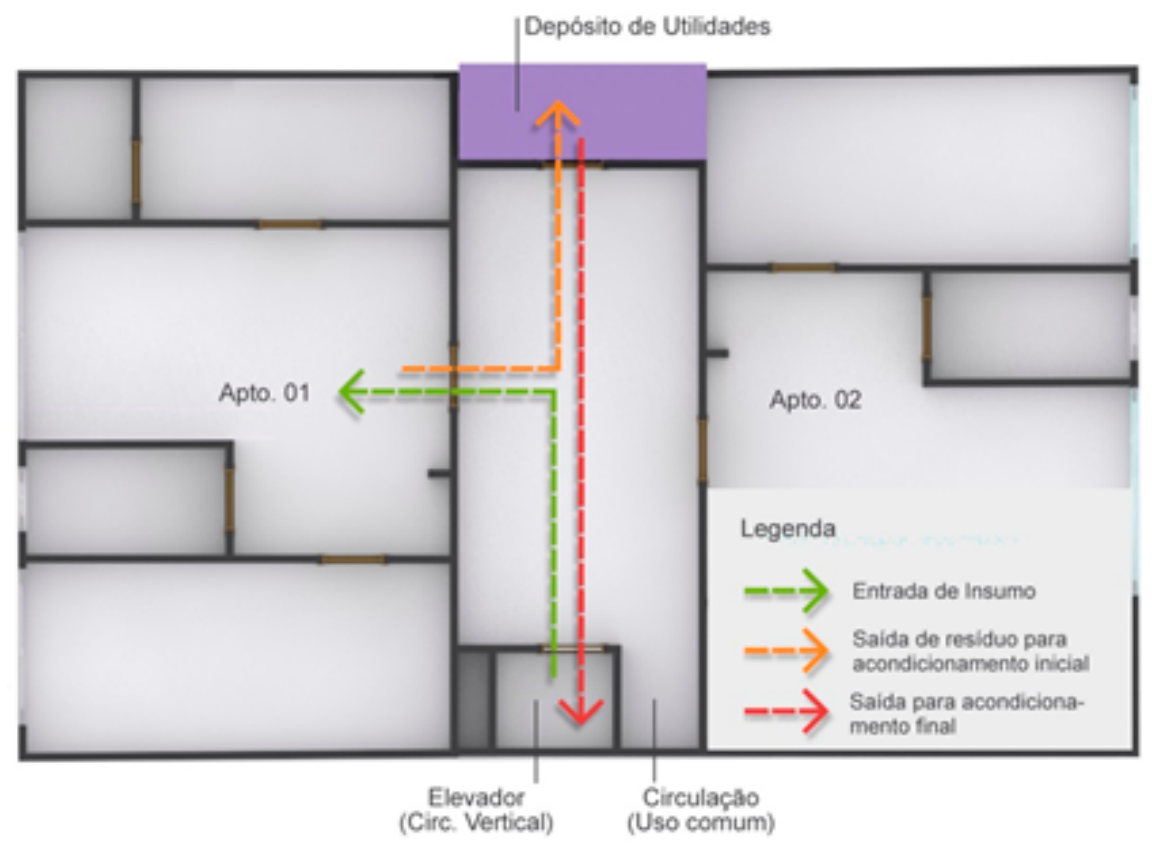

Fonte: elaborada pelos autores (2015)

Nesse espaço também estaria a área técnica de cada andar, com as caixas de distribuição de gás, iluminação, hidráulica e lógica, otimizando o espaço de uso comum, bem como o uso interno de cada apartamento/escritório.

A segunda etapa do processo de serviço para essa edificação estaria na acomodação dos dispositivos na área de garagem ou na área próxima ao lixo convencional. Importante que seja na área privativa do condomínio, para que os usuários sintam-se ainda 'proprietários' dos RCC gerados.

Com relação ao dispositivo de transporte dos RCC, foram considerados os seguintes requisitos: (1) passar em todas as portas; (2) reduzir a fadiga muscular do funcionário; (3) priorizar o acondicionamento, triagem e transportes internos em um único contenedor, diminuindo custos, tempo nos traslados de material; 
(4) ocupar o menor espaço possível na área prevista para o descarte final ( $240 \times 500 \mathrm{~cm}=$ equivalente a uma vaga de garagem). Depois dos estudos realizados, foi idealizada uma proposta de serviço, como uma alternativa à caçamba estacionária, com os parâmetros para desenvolvimento, como demonstra a Figura 4.

Figura 4 - Parâmetros de desenvolvimento da proposta de serviço Tornar o serviço atraente ao gerador

Como fazer com que o cliente opte pelo novo serviço, se hoje a caçamba estacionária cumpre a funçâo, que è 'eliminar' o residuo? Foi consenso nas discussōes do grupo que a consciência ambiental seria o primeiro passo para uma nova postura;
Fazer parcerias com condominios e sindicos. ancorados na NBR 16.280 , que dispōe sobre as diretrizes de um 'plano de reforma' que se torna obrigatório e em especial, da responsabilidade das incorporadoras e construtoras, projetistas e sindicos em relaçăo às reformas realizadas nas áreas comuns e privativas do edificio (ABNT, 2014).

\section{Transparência}

O cliente devera saber qual o destino do seu RCC, pois ele está pagando por isso.
Ele deverá perceber que o residuo recolhido por esse novo serviço terá um destino mais nobre que o serviço convencional.

Leis, impostos e incentivos fiscais e financeiros

- Viabilizar novas leis e um aumento de impostos sobre o descarte do RCC, proporcionando uma penalizaçăo financeira ao gerador, que irá ter consciência que irá gastar da próxima vez que eliminar o residuo;
- Remunerar o gerador sobre o residuo coletado em bom estado, de forma a incentivar a correta separaçăo e bom estado dos materiais.

\section{Treinamento}

O gerador nåo tem o sentimento de responsabilidade sobre o RCC após a sua ida para a caçamba estacionária, jả no ambiente público. A capacitação por meio de cartilhas, palestras, cursos, aplicativos on-line ou envolvimento dos agentes da cadeia produtiva da construção civil, para informar sobre esse novo serviço.
A conscientizaçăo sobre as vantagens desse novo serviço deve acontecer desde a etapa de projeto até o descarte no aterro sanitário.

Fonte: primária (2015) 
A partir dos parâmetros, foi criado um infográfico (Figura 5), que mostra a idealização do sistema/serviço considerando uma reforma em um edifício de apartamentos (as etapas estão descritas logo após a figura).

Figura 5 - Infográfico da proposta do sistema/serviço

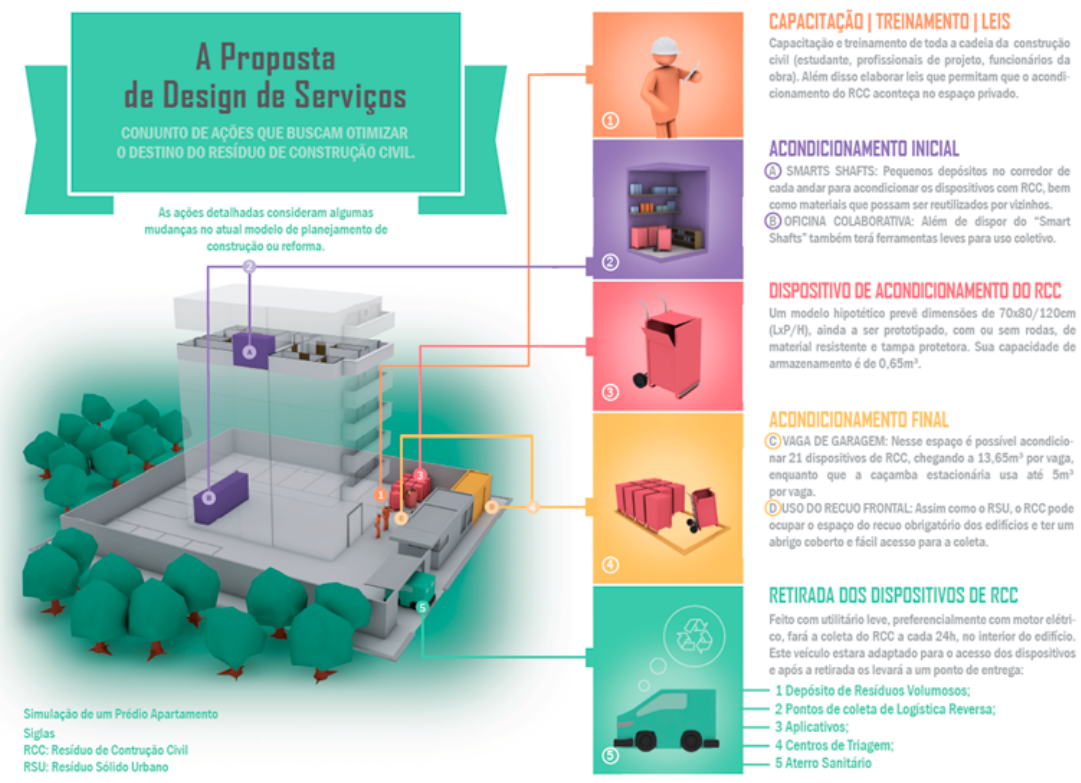

Fonte: primária (2015)

1. O serviço prevê a capacitação e treinamento de toda a cadeia da construção civil, desde o estudante, passando pelos profissionais de projeto, até os funcionários da obra, por meio de cursos, ensino a distância (EAD), palestras e manuais de boas práticas. Praticar as leis existentes e instigar novas, que permitam que o correto acondicionamento dos RCC aconteça no espaço privado, ancorado em normas como a NBR 16.280 e que tenham cunho informativo e propositivo. 
2. Prever locais internos no edifício, seja em novos projetos, seja nos já construídos, que promovam uma 'corrente colaborativa', como:

- Depósito de utilidades: nas novas obras de prédios, prever pequenos depósitos no corredor de cada andar (prédios novos) para acondicionar os dispositivos móveis com RCC, bem como materiais que possam ser reutilizados por vizinhos, como restos de tinta, metais sanitários, spots de iluminação, entre outros produtos. A proposta também prevê dispor de pequenos objetos de uso esporádico, mas que ocupam espaço nas áreas privativas dos apartamentos, como caixa de ferramentas leves para uso coletivo, furadeira, escadas de pequeno e médio porte. Também estariam alocados nesse espaço a área de manutenção de rede elétrica, lógica, hidráulica e gás, chamados shafts.

- Oficina colaborativa: local previsto no andar térreo, um pouco maior que os depósitos de utilidades, que além de dispor dos utensílios citados no item 2.1 também teria bancadas para trabalho.

3. Dispositivo para acondicionar o RCC com dimensões de $70 \mathrm{x}$ $80 / 120$, com ou sem rodas, de material resistente e tampa protetora com capacidade de armazenamento de 0,65 $\mathrm{m}^{3}$.

4. Baseado em leis correlatas, os RCC teriam dois possíveis locais para acondicionamento final, dependendo das condições de espaço no edifício:

- Vaga de garagem: o código de posturas do município prevêvaga com dimensões de 2,40 × 5,00 m para automóveis, totalizando uma área de $12 \mathrm{~m}^{2}$. Nesse espaço seria possível acondicionar 21 dispositivos de RCC, chegando a 13,65 $\mathrm{m}^{3}$ por vaga, enquanto que a caçamba estacionária usaria a mesma vaga e forneceria entre 3 e $5 \mathrm{~m}^{3}$ por vaga.

- Uso do recuo frontal: os RCC poderiam ocupar o espaço do 
recuo obrigatório dos edifícios e ter um abrigo coberto e fácil acesso para a coleta, sendo disponibilizado pelo condomínio, assim como já acontece com o RESÍDUO SÓLIDO URBANO (RSU).

5. Coleta dos dispositivos de RCC: seria realizada por meio de um utilitário leve, preferencialmente com motor elétrico a cada 24h. Esse veículo estaria adaptado para o acesso e acomodação dos dispositivos.

5a. Aplicativos: O serviço pode ser disponibilizado por um aplicativo para smartphones e tablets, com o intuito de torná-lo ágil, prático, atraente e amigável ao gerador de resíduos e população em geral, facilitando o acesso às informações, horários de coleta, orientação sobre separação e acondicionamento, identificação e denúncia de descarte em áreas proibidas, consultoria de projetos, entre outros assuntos que podem ser discutidos em estudos futuros. É importante fazer com que a população e o gerador de RCC sintamse parte do processo e exerça seu papel como cidadão.

5b. Destino do resíduo: Após a coleta dos dispositivos de RCC, o utilitário levará até um ponto de entrega que, dependendo do tipo de resíduo, poderá ser:

- Depósito de resíduos volumosos: abrigaria os materiais passíveis de reúso como: esquadrias, louças, metais, pisos, isolamentos e móveis, assim como sobras de tintas. O serviço se estenderia a consultorias de projeto arquitetônico, em que seriam adaptados os materiais às necessidades dos clientes, gerando mais uma experiência positiva no processo;

- Pontos de coleta para logística reversa: atualmente, o Programa Nacional de Resíduos Sólidos (PNRS) prevê o retorno de apenas seis produtos para as empresas responsáveis. Na condição ideal, o maior número possível de RCC deveria retornar para 
a empresa de origem, principalmente os de Classe $C$ (não recicláveis) e $D$ (perigosos), pois as empresas fabricantes devem ter responsabilidade sobre eles. De acordo com o PNRS (2010), é importante no planejamento estratégico das organizações adequá-las à legislação do meio ambiente atual, para o correto destino dos RCC. Os depósitos de resíduos volumosos poderiam funcionar como centros de coleta e triagem para as empresas.

- Centros de triagem: os resíduos de Classe A e B, como derivados do concreto e madeira, não reaproveitados para o depósito de resíduos volumosos, seriam levados aos centros de triagem, para a fabricação de agregados (areia reciclada, pedrisco reciclado, rachão) e recolocados no mercado como agregados reciclados.

- Aterro sanitário: resíduos sem potencial de aproveitamento ou reciclagem no próprio canteiro de obras seriam destinados adequadamente aos aterros sanitários, onde encerra o ciclo de vida do produto.

\section{CONSIDERAÇÕES FINAIS}

Por meio das pesquisas bibliográficas, constatou-se que leis e normas técnicas existem e são bem elaboradas, porém pouco aplicadas. As cidades não estão totalmente preparadas para receber os RCC de forma correta, e embora a eliminação dos resíduos da construção civil seja a solução mais favorável para a minimização dos impactos ambientais, é necessário considerar que será fruto de um processo lento e gradativo, exigindo a cooperação de todos os agentes da cadeia produtiva.

As ferramentas do Design foram fundamentais para o entendimento do processo e a elaboração do sistema de 
acondicionamento e transporte, e os principais resultados que poderão surgir por meio do serviço proposto são: (1) benefícios ao meio ambiente e à qualidade de vida das cidades; (2) redução da utilização dos recursos naturais, que são finitos; (3) redução das áreas necessárias para aterros; (4) a produção de agregados com base no entulho, como blocos e base de pavimentação; (5) a melhoria da poluição visual e mobilidade, com menos caçambas estacionárias em vias públicas; (6) a limpeza da obra; (7) funcionários trabalhando de forma correta e ergonômica.

Portanto, o serviço proposto vai além do simples fato de acondicionar, separar e transportar de maneira correta os RCC. Visa implantar uma nova cultura sustentável na cadeia produtiva da construção civil. 


\section{REFERÊNCIAS}

ASSOCIAÇÃO BRASILEIRA DE EMPRESAS DE LIMPEZA PÚBLICA E RESÍDUOS ESPECIAIS (ABRELPE). Panorama dos Resíduos Sólidos no Brasil: manual de Boas Práticas. São Paulo, 2010.

. NBR 16.280: Reforma em edificações-Sistema de gestão de reformas-Requisitos. Rio de Janeiro, 2014.

AGOPYAN, V., JOHN, V. M. O desafio da sustentabilidade na construção civil. São Paulo: Blucher, 2012.

BRASIL. Ministério do Meio Ambiente. Guia para elaboração dos Planos de Gestão de Resíduos Sólidos. Brasília, 2011.

CONAMA. CONSELHO NACIONAL DO MEIO AMBIENTE. Resolução 307/2002. Destino de Resíduos da Construção e Demolição, 2002. Disponível em: <http://mma.gov.br/download/resolucao/federal/ conama2002.pdf >. Acesso em: 28 abr. 2013.

JOHN,V.M. Reciclagem deresíduos na construção civil: contribuição à metodologia de pesquisa e desenvolvimento. Tese (Livre Docência) - USP, São Paulo, 2000.

LIMA, R. S.; LIMA, R. R. R. Guia para elaboração de projeto de gerenciamento de resíduos da construção civil. Paraná: CREA-PR, 2009.

MANZINI, E.; VEZZOLI, C. O desenvolvimento de produtos sustentáveis: os requisitos ambientais dos produtos industriais. São Paulo: EDUSP, 2002.

PINTO, T. P. Gestão ambiental de resíduos da construção civil. São Paulo, 2005.

. Reciclagem/destinação de resíduos. Revista Téchne, São Paulo, n.162, p. 59, set. 2010. 
PINTO, T. P.; GONZÁLEZ, J. L. R. Manejo e Gestão de Resíduos da Construção Civil: como implantar um Sistema de Manejo e Gestão dos Resíduos da Construção Civil nos municípios. Brasília: Caixa Econômica Federal; Ministério das Cidades: Ministério do Meio Ambiente, 2005.

ROAF, S.; THOMAS, S. Ecohouse: a casa ambientalmente sustentável. São Paulo: Bookman, 2006.

ROGERS, R.; GUMUCHDJIAN, P. Cidades para um pequeno planeta. 1. ed., 6. impressão. Barcelona: Gustavo Gili, 2013.

SOUZA, P. F. A. Sustentabilidade e responsabilidade social no design do produto: rumo à definição de indicadores. 2007. 294 f. Tese (Doutorado) - Faculdade de Arquitetura e Urbanismo, Universidade de São Paulo, São Paulo, 2007.

SOUZA, M. Design de serviços: seu cliente vivenciando uma notável experiência de atendimento. São Paulo: Clube dos Autores, 2008.

VEZZOLI, C. Design de sistemas para sustentabilidade: teoria e ferramentas para o design sustentável de "sistemas de satisfação". Salvador: EDUFBA, 2010.

ZEITHAML, V. A.; BITNER, M. J.; GREMLER, D. D. Marketing de Serviços: a empresa com foco no cliente. Nova lorque: Bookman, 2014. 